\title{
Reforma Gerencial em Contexto Local: Estudo Comparado dos Municípios de Osasco e Niterói
}

\section{Public Management Reform in a Local Context: a Comparative Study Between the Municipalities of Osasco and}

Niterói

\author{
Marilia Sorrini Peres Ortiz \\ Mestre em Administração Pública e Governo / Fundação Getúlio Vargas \\ Subsecretária de Planejamento e Orçamento da Secretaria de Planejamento, Modernização da Gestão e Controle / Prefeitura Municipal de Niterói \\ http://lattes.cnpq.br/5311619297842415 \\ orcid.org/0000-0002-9851-0812 \\ marisportiz@gmail.com \\ Anny Karine de Medeiros \\ Doutoranda em Administração Pública e Governo / Fundação Getúlio Vargas \\ Professora / Centro Universitário Senac Santo Amaro. Pesquisadora / Centro de Estudos em Administração Pública e Governo \\ http://lattes.cnpq.br/7646191390238946 \\ orcid.org/0000-0002-9208-5720 \\ annykmedeiros@gmail.com
}

Resumo: No contexto brasileiro as reformas gerenciais iniciadas na década de 1990 são legados sólidos com experiências em âmbito federal e também subnacional. Após duas décadas deste movimento, as experiências municipais são mais recentes - e quase residuais se desconsiderarmos as capitais, havendo pouco acúmulo sobre os resultados obtidos nestes casos. O trabalho de Abrucio e Gaetani (2006) identificou como fatores para a formação de alianças e coalizões que influenciam a reforma gerencial em estados: a) o efeito da questão fiscal; b) inovacões administrativas que geraram path dependence; c) o peso dos policies entrepreneurs; e d) a "janela de oportunidade" aberta. Partindo dessa categorização, propõe-se uma pesquisa empírico-teórica que toma como referência o estudo comparado de dois casos, que configuram experiências recentes de reformas gerenciais no âmbito municipal, quais sejam: Osasco e Niterói, a fim de verificar os elementos da categorização e ampliar a discussão para casos contemporâneos.

Palavras-chave: Municípios; Planejamento municipal; Reforma do aparato estatal.

Abstract: The Brazilian public management reform initiated in the 1990s is a solid legacy with proven representations in federal and sub-national levels. After two decades of this movement, the municipal experiences are more recent - and almost residual, if we disregard the capital cities. There has been few academic addition on the results obtained in municipal cases. The research of Abrucio and Gaetani (2006) identified as factors for the formation of alliances and coalitions that influence the management reform in states: a) the effect of the tax issue; b) administrative innovations that generated path dependence; c) the weight of the "policies entrepreneurs"; and d) the "window of opportunity" opened. Based on this categorization, we propose an empirical and theoretical research that takes as reference the study of two cases that set recent experiences of management reforms in a municipal level, in the cities of Osasco and Niterói, in order to verify these elements of categorization and expand the discussion to contemporary cases.

Keywords: Municipalities. Municipal planning. Reform of the State apparatus.

Texto completo em português: http://www.apgs.ufv.br

Full text in Portuguese: http://www.apgs.ufv.br

\section{INTRODUÇ̃̃O}

A agenda de Reforma do Estado iniciada no Brasil, em meados da década de 1990, foi instaurada sob a prerrogativa de adotar princípios da Nova Gestão Pública (New Public Mannagement) já experimentados, ainda na década de 1980, por países como Grã Bretanha, Nova Zelândia e Austrália e, no início dos anos 1990, pelos Estados Unidos (Schwarz, 2009).

A partir da década de 1990 a difusão desse modelo como legado para promover a eficiência da gestão pública, em oposição às práticas patrimonialistas e à administração burocrática, se deu de forma ampla no país em diversos entes da Federação. O Plano Diretor da Reforma do Estado, criado pelo então Ministério da Administração Federal e Reforma do Estado (MARE), foi fundamental para consolidar as propostas de redução do aparato estatal concomitante à ampliação do uso de instrumentos gerenciais, e ao fortalecimento do núcleo estratégico, à implantação de agências executivas e das organizações sociais (Bresser Pereira, 1998).

No contexto brasileiro é possível afirmar que as reformas gerenciais podem ser consideradas como legados sólidos, com acúmulo de experiências em âmbito federal e subnacional (Bechelaine; Silveira; Neves, 2012). A Reforma do Estado, proposta em âmbito federal, tomou corpo e se desenvolveu, incentivando estados e municípios a seguir tendência semelhante. A partir da experiência pioneira a nível estadual do "Choque de Gestão" mineiro (2003-2010), diversas práticas de reforma gerencial foram implementadas por estados como Pernambuco, Sergipe, Rio de Janeiro e São Paulo (Pacheco, 2006). Mais recentemente municípios têm adotado políticas reformistas na esfera da gestão como forma de gerir e monitorar os programas de governo, como Rio de Janeiro (RJ), Porto Alegre (RS), Salvador (BA), Belo Horizonte (MG), dentre outrosi.

Convém ressaltar que a difusão de experiências influenciadas pela agenda reformista em estados e municípios não é homogênea, tendo em vista que diversos entes no âmbito subnacional têm implementado inovações e contribuído para a disseminação de ideias de forma "fluida e fragmentada" (Abrucio \& Gaetani, 2006). Ainda que não seja possível estabelecer um modelo único de reforma gerencial, Bresser Pereira (1998) reconhece um marco 
institucional comum pontuado pela: a) delimitação da área de atuação do Estado, com base nas suas atividades principais, exclusivas e auxiliares; b) pela organização da execução das atividades exclusivas e não-exclusivas do Estado, considerando a participação dos órgãos da administração direta, das agências executivas e reguladoras, das organizações sociais e das empresas privadas; c) pela descentralização político-administrativa dos entes subnacionais; e d) pela implementação gradual com metas de curto, médio e longo prazos, com o objetivo de aumentar a eficiência.

A adoção de modelo de gestão governamental, independente do posicionamento político de cada governo, cada vez mais tem se apresentado como uma necessidade frente às obrigações legais impostas. Como exemplos, é possível citar a Lei de Responsabilidade Fiscal (Lei Complementar ํㅜ 101 de 04 de maio de 2000), que conduziu os municípios a se comprometerem com o ajuste fiscal, e a Lei da Transparência (Lei Complementar no 131 de 27 de maio de 2009), que estabeleceu obrigações em relação ao aumento da transparência e accountability das contas públicas. Mais recentemente, a Lei de Acesso à Informação (Lei no 12.527 de 2011) levou a novo patamar a disponibilidade de informações. Tais exigências legais têm influenciado estados e municípios a priorizar iniciativas de modernização da gestão, como o planejamento estratégico de médio e longo prazo, a pactuação de metas entre governo e sociedade civil, o redesenho de processos, a utilização de instrumentos de gestão privada e de Tecnologias de Informação e Comunicação (TICs) e a gestão por resultados. Especificamente, em relação aos municípios, tais exigências referentes à modernização da gestão têm se tornado cada vez mais necessárias. Isso porque, com o advento da Constituição Federal de 1988, os governos locais passaram a lidar com novas atribuições, antes de responsabilidade, dos estados e da Federação. Com isso, as gestões municipais passaram a ser o foco da inovação, já que as novas necessidades criaram uma situação favorável para a busca por novas formas de administrar as cidades (Crantschaninov \& Medeiros, 2012). Contudo, à exceção das capitais que, em maior ou menor grau, implantaram medidas em prol da eficiência administrativa, a reforma gerencial tem ocorrido de forma residual nos demais municípios. Um estudo realizado por Freitas Jr. (2009) procurou verificar como o modelo do "Choque de Gestão" afetou os municípios pertencentes ao estado de Minas Gerais e, para tanto, analisou 177 municípios do sul do Estado de Minas Gerais, verificando que nenhum deles adotou o referido modelo de forma substancial, resistindo às estruturas arcaicas, no modo de gerir a máquina pública. Foi constatado ainda que a orientação partidária não influenciou a maior ou menor adoção de uma agenda reformista de gestão.

A fim de contribuir com o entendimento do atual cenário das reformas gerenciais em municípios, propõe-se uma pesquisa empírico-teórica, que visa analisar como a agenda de Reforma do Estado é absorvida por municípios 20 anos após seu surgimento. Toma-se como referência o estudo de dois casos que configuram experiências recentes de reformas gerenciais no âmbito municipal, quais sejam: Osasco e Niterói, a fim de verificar estes elementos e ampliar a discussão para casos contemporâneos. A análise dos casos municipais é realizada com base no trabalho de Abrucio e Gaetani (2006), que identificaram diferentes fatores para a formação de alianças e coalizões reformistas nos estados brasileiros. O presente artigo vale-se das contribuições destes autores para aplicá-las à compreensão da realidade dos dois municípios brasileiros supracitados, por acumularem experiências recentes de políticas que priorizam a eficiência na gestão pública.

$O$ artigo subdivide-se nesta introdução, que trata de um panorama geral sobre o legado da Reforma Gerencial, e a Nova Gestão Pública em contexto subnacional, e, posteriormente, discute-se a metodologia adotada e abordagens dos estudos de caso de Osasco e Niterói, que embasam a análise comparada e a discussão crítica, a fim de traçar as considerações finais do presente artigo.

\section{METODOLOGIA DO ESTUDO}

As questões que motivaram o presente artigo buscam esclarecer se municípios são, de fato, menos sensíveis à agenda reformista, conforme as experiências residuais existentes tenderiam a demonstrar. Para tanto, busca-se investigar neste trabalho quais fatores tendem a viabilizar a reforma gerencial em municípios brasileiros. Como método, o artigo realiza o estudo comparado de dois casos de municípios que possuem históricos recentes de priorização política da reforma da gestão pública Osasco/SP e Niterói/RJ - buscando delinear o contexto que induziu a priorização desta agenda nos dois casos.

A opção pelos estudos de caso foi realizada por considerar que esta abordagem comparativa permite iluminar alguns pontos cruciais a respeito dos elementos propulsores da reforma gerencial em contexto local que poderão ser observados de maneira mais extensiva em trabalhos de maior fôlego, tendo em vista que os municípios possuem realidades e relações múltiplas e complexas.

Os dados qualitativos utilizados para realizar os estudos de caso foram obtidos por meio de mídia impressa, discursos oficiais e levantamento do histórico institucional junto aos gestores, buscando verificar os fatores que influenciaram positivamente para o advento da agenda reformista nos municípios.

\subsection{A escolha dos estudos de caso}

A escolha de tais municípios para estabelecer uma análise comparativa sobre os fatores que viabilizam a reforma gerencial deu-se com base nos seguintes fatores:

\subsubsection{Características semelhantes no contexto metropolitano}

Osasco e Niterói são municípios pertencentes, respectivamente, à Região Metropolitana de São Paulo e Rio de Janeiro e, ambos se destacam por serem municípios de grande relevância no contexto metropolitano, seja pela dinamização da economia nessas regiões, ou pela população que concentram. Osasco possui 691.652 habitantes (IBGE, 2010), IDH-M de 0,776 e PIB de 39,2 bilhões de reais, sendo o 4ํmaior do Estado de São Paulo. Por sua vez, Niterói concentra 487.327 habitantes (IBGE, 
2010), IDH-M de 0,837 (PNUD, 2010) e PIB de 11,2 bilhões de reais, sendo o 5ำ maior do Estado do Rio de Janeiro.

\subsubsection{Experiências recentes de políticas orientadas ao aprimoramento da gestão}

Os municípios selecionados para estudo de caso têm se destacado por elencar a agenda de gestão, dentro das prioridades políticas, desde o início dos mandatos iniciados em 2013. Ainda que preservem características reformistas distintas, entre os fatores comuns que corroboram a ideia de priorização da agenda de gestão estão: a criação da Secretaria Municipal de Planejamento e Gestão (SEPLAG), em Osasco, e de Planejamento, Modernização da Gestão e Controle (SEPLAG) em Niterói; a aprovação da linha de financiamento do Programa de Modernização da Administração Tributária (PMAT) e da Gestão dos Setores Sociais Básicos do Banco Nacional de Desenvolvimento Econômico e Social (BNDES) ${ }^{\mathrm{ii}}$ de apoio a projetos de modernização da gestão municipal; bem como a implementação de estratégias orientadas pelo modelo de gestão por resultados.

\subsubsection{Filiação partidária}

As gestões de Osasco e Niterói lideradas, respectivamente, pelos prefeitos Jorge Lapas e Rodrigo Neves foram, em seu início, orientadas pela mesma filiação partidária: o Partido dos Trabalhadores (PT), sendo que ambos vieram a se desfiliar do partido ao longo da gestão. Jorge Lapas filiou-se ao Partido Democrático Trabalhista (PDT), ao passo que Rodrigo Neves filiouse ao Partido Verde (PV). Este fator de mesma filiação políticopartidária fora relevante na escolha dos municípios, tendo em vista que os casos de reforma gerencial de maior expressividade no país se deram em contextos marcados por gestões do Partido da Social Democracia Brasileira (PSDB) - Governo Fernando Henrique Cardoso (1995 - 2003) e Governo Aécio Neves (2003 - 2010) - o que acentua o interesse por compreender os fatores que mobilizam a priorização da agenda reformista em gestões de partidos de esquerda.

\subsection{Referencial teórico para análise}

Um dos pilares do chamado New Public Management (NPM) é a busca por ampliar a eficiência e garantir efetividade nas políticas públicas (Moynihan \& Pandey, 2004; MOynihan \& PAndey, 2010; O'Toole \& Meier, 2015). Os autores detalham como as experiências de ampliação de eficiência têm se espalhado a partir deste movimento de NPM:

The New Public Management created a system of performance accountability whereby political sovereigns set goals for bureaucracy and permit bureaucratic discretion in attaining those goals with a process for evaluation of results. (Moynihan 2008; Pollitt \& Bouckaert; 2000 apud O'Toole E Meier, 2015).

É também em âmbito internacional que surgem estudos que buscam compreender como o setor público se apropria destes mecanismos. Moynihan e Pandey (2004) apontam que, a partir dos anos 1980, vive-se a tendência emergente da ênfase em resultados e melhores performances de gestão, na expectativa de que um bom governo seria capaz de buscar modificar suas estruturas a fim de promover uma performance ainda melhor. Esta tendência se reflete na crescente literatura voltada ao estudo destes instrumentos. No entanto, Moynihan e Pandey (2004) acreditam que as teorias existentes ainda não foram capazes de desvendar a "caixa preta" do setor público, pois ainda não é possível ter clareza sobre quais processos administrativos podem garantir melhores resultados em qualquer organização pública.

Com vistas a compreender de que maneira os municípios brasileiros têm se apropriado dos mecanismos de NPM, buscou-se uma teoria que permitisse iluminar a análise dos fatores e condições que tenderiam a viabilizar a agenda reformista destacando os projetos escolhidos para compor este "pacote de reforma gerencial" em cada um dos casos analisados.

Para tanto, o anteparo teórico selecionado para a análise dos casos de Osasco e Niterói foi o artigo de Abrucio e Gaetani (2006), que faz um balanço das reformas nas políticas de gestão pública nas administrações públicas estaduais iniciadas após a experiência iniciada pelo Governo Federal em 1995. Os autores avaliam que as reformas ocorridas nos estados brasileiros seguem modelos heterogêneos, pois ainda que a experiência federal possa ter inspirado o ciclo de reformas, as inovações nos estados na área de gestão pública aconteceram de forma independente, não se baseando necessariamente no modelo implantado por Bresser Pereira (1995).

Conforme mencionado anteriormente, os autores avaliam a relevância de compreender as inovações provenientes do movimento de reforma gerencial, pois "destrinchar os elementos constituintes das coalizões reformistas potencialmente ganhadoras é condição para a sua compreensão, construção e fortalecimento" (Abrucio \& Gaetani, 2006; p. 23).

O trabalho de Abrucio e Gaetani (2006) delimita quatro fatores que favorecem alianças e coalizões em torno da agenda de reforma gerencial nos estados, dentre eles: a) o efeito da questão fiscal; b) inovações administrativas que geraram path dependence; c) o peso dos policies entrepreneurs; e d) a "janela de oportunidade" aberta pela ideia mobilizadora do "Choque de Gestão".

No que diz respeito ao fator elencado da questão fiscal, os parâmetros obrigatórios estabelecidos pela Lei de Responsabilidade Fiscal (LRF) exigiu dos entes federativos assumir compromissos efetivos com o ajuste de suas contas. Tal fator tem impulsionado sobremaneira esforços dos governos estaduais e municipais em adotar medidas voltadas ao aumento da eficiência e economicidade para que os ditames da Lei sejam cumpridos.

Em relação ao path dependence ${ }^{i i i}$, Abrucio e Gaetani (2006, p. 15) destacam que diversas políticas implementadas pelos governos estaduais geraram boas avaliações e apoio social, chegando inclusive a um estágio de "não retorno". Na realidade dos estados são destacadas como principais experiências: os Centros de Atendimento Integrados, compras governamentais, governo eletrônico e coalizão em torno do Plano Plurianual, vinculando metas ao orçamento. Em um número menor de experiências, porém 
já relevantes do ponto de vista de disseminação, estão a profissionalização dos gestores de políticas públicas (carreiras de gestores e escolas de governo) e a contratualização de resultados por meio de Organizações Sociais.

Em relação à disseminação das "boas práticas" os autores ressaltam a existência de gestores que participaram da reforma no governo federal em secretarias estaduais, fóruns federativos, no Conselho Nacional de Secretários de Estado da Administração (Consad), no Programa Nacional de Apoio à Gestão Pública (PNAGE) e bancos de experiências de premiações realizadas pela FGV-SP/Fundação Ford, Ministério do Planejamento, Orçamento e Gestão (MPOG), entre outras.

Os últimos dois elementos destacados pelos autores - os policy entrepreuners (empreendedores de políticas públicas) e a janela de oportunidade aberta - são baseados no "Modelo de Fluxos Múltiplos", de John Kingdon (1995), que propõe uma análise de três estágios decisórios que impulsionam a formulação da agenda governamental: fluxo de problemas (problem), fluxo de soluções ou alternativas (policies) e fluxo político (politics).

Kingdon (1995) defende que o encontro desses três fluxos é impulsionado pela participação de atores visíveis e invisíveis e por empreendedores de políticas que viabilizam a "janela aberta", garantindo a chegada de uma determinada questão pública à agenda governamental. Atores visíveis são aqueles considerados os mais influentes, uma vez que participam ativamente dos fluxos de problemas e de política para viabilizar oportunidades de acesso à agenda governamental. Por sua vez, os atores invisíveis são considerados aqueles que geram ideias e as colocam em circulação em uma comunidade (policy communities) para gerar alternativas e soluções.

Aplicando a estrutura teórica de Kingdon (1995) à proposta de Abrucio e Gaetani (2006), o papel dos dirigentes públicos é decisivo, principalmente em relação à conciliação da visão técnica com a estratégia política, para dar sentido positivo à agenda governamental e criar condições para a abertura de janela de oportunidade. Por sua vez, o papel dos atores invisíveis deve ser visto também como relevante nesse processo de formar alianças e coalizões reformistas. A disseminação de experiências inovadoras na área de gestão e sua viabilização em diferentes contextos nos estados vinculam-se à expertise acumulada de gestores e técnicos, responsáveis pela execução das políticas públicas.

\section{A AGENDA REFORMISTA NOS MUNICÍPIOS SEGUNDO CASOS CONTEMPORÂNEOS}

Nesta seção são abordados os casos destacados para a análise: municípios de Osasco e Niterói. Dessa forma, o estudo foi realizado principalmente a partir da atuação da SEPLAG em ambos os casos estudados. Portanto, essa estrutura da administração direta nos municípios, assim como em outros casos verificados, é onde prioritariamente são lideradas as reformas na área de gestão.

A narrativa dos casos é estruturada com base na descrição do contexto que levou à priorização da agenda reformista, à implantação da cultura de planejamento estratégico e o modelo de acordo para resultados, às iniciativas de modernização da gestão (atuais e perspectivas futuras) e a identificação dos principais atores da reforma.

\subsection{O caso do município de Osasco}

A prioridade dada pelo governo atual, no planejamento estratégico voltado para resultados, surge a partir da criação e atuação da Secretaria de Planejamento e Gestão (SEPLAG), órgão destacado para protagonizar as reformas necessárias na administração pública do município. O órgão fora criado pela gestão do prefeito Jorge Lapas (PT) quando este assumiu o governo como prefeito em janeiro de 2013.

A SEPLAG Osasco originou-se da então Secretaria de Governo, responsável na gestão anterior pela articulação transversal das secretarias municipais e que tinha como seu Secretário na gestão anterior o atual Prefeito Jorge Lapas. A grande motivação para a criação da institucionalidade da SEPLAG no município de Osasco deveu-se à necessidade de aprimorar a gestão e executar os projetos pactuados com órgãos externos, em especial o Governo Federal.

\subsubsection{A cultura de planejamento estratégico e o modelo de acordo de resultados}

Baseando-se na experiência de estados como Minas Gerais e Acre, foi proposto no município de Osasco (SP) um modelo de gestão para resultados baseada no planejamento estratégico, vinculado ao Plano Plurianual (PPA), cujas metas foram estabelecidas a partir do movimento "Osasco 50 anos", criado para definir as metas para o cinquentenário da cidade, completo em 2012. Este processo contou com 75 reuniões em 09 eixos temáticos, e foi encabeçado pela então Secretaria de Governo, tendo participação dos sindicatos, empresários, sociedade civil organizada e governo.

As metas do "Osasco 50 anos" foram a base para o Plano de Governo do então candidato a prefeito Jorge Lapas (PT), que ao ser eleito cria a SEPLAG Osasco, garantindo assim a atuação do planejamento centralizado, acompanhamento por indicadores, monitoramento dos projetos e apoio institucional.

A SEPLAG Osasco inicia então sua atuação propondo um modelo de gestão para resultados baseado no estabelecimento de Acordos de Resultado pactuados entre o órgão, todas as secretarias gestoras e Prefeito, com apoio de consultoria específica para este projeto, no qual constam objetivos estratégicos, projetos prioritários e indicadores de projeto e de resultado. As únicas secretarias que não tiveram acordos estabelecidos, apesar de também terem seus projetos estratégicos identificados, foram as consideradas "secretarias meio", como Administração, Finanças e Assuntos Jurídicos. Assim, as metas inicialmente formuladas junto à população foram sistematizadas em um processo junto à alta cúpula de gestão.

A aproximação dos objetivos estratégicos às peças orçamentárias buscou atrelar práticas de acompanhamento por resultados às ferramentas legais de controle e monitoramento a fim 
de tornar o PPA mais próximo da realidade da Prefeitura e efetiválo como ferramenta de planejamento e monitoramento. O processo de planejamento estratégico no município de Osasco buscou articular as peças orçamentárias, o que configurou um avanço e, ao mesmo tempo, um desafio a ser alcançado. Isto porque o planejamento estratégico, calcado em ferramentas gerenciais para a administração, segue lógica distinta do planejamento realizado pela administração pública brasileira, fortemente calcada em instrumentos de finanças públicas.

Concluída a fase de implementação desse primeiro movimento, a SEPLAG Osasco passa a liderar a construção de planos temáticos, anuais e plurianuais junto aos demais órgãos municipais e entidades, por meio dos Acordos de Resultado.

A reforma gerencial aplicada no município focou ainda o fortalecimento institucional, em especial estruturando relações com os demais entes federados, órgãos congêneres, ao retomar projetos fundamentais para o desenvolvimento do município, fortalecer a captação de recursos e a implementação de projetos pactuados cujos recursos estavam garantidos, entretanto a execução ainda não iniciada.

O monitoramento da execução dos projetos estruturadores dos Acordos de Resultado é acompanhado por um Escritório de Gestão de Projetos Estratégicos, referenciado no Departamento de Fortalecimento Institucional, que se relaciona diretamente com os Escritórios Locais de cada secretaria para acompanhamento dos projetos estratégicos, e aqueles conveniados com outros entes federados.

Além do monitoramento diário, há reuniões mensais para monitoramento, e os resultados e problemas encontrados são apresentados periodicamente ao prefeito, por meio das Salas de Situação realizadas para cada secretaria, que buscam dar soluções e dissolver gargalos para melhor continuidade dos projetos estratégicos. Para tanto, foram realizadas diversas capacitações tanto do quanto para o corpo técnico das secretarias, em busca da implantação da cultura de gestão para resultados.

\subsubsection{Iniciativas de modernização da gestão}

No caso do município de Osasco a modernização dos sistemas de informação é foco de projeto financiado pelo PMAT, em 2015, continuação de financiamento executado a partir de 2010. Este projeto busca modernizar a administração pública como um todo, atuando na informatização da área tributária, patrimonial, orçamentária, financeira e a gestão dos serviços básicos de saúde e assistência social.

O PMAT aprovado em 2010 permitiu a atualização do cadastro mobiliário e imobiliário do município, fornecendo importantes ferramentas para planejamento urbano, como o georreferenciamento do município e a revisão da planta genérica de valores, cuja atualização impactou em crescimento de 55\% na arrecadação de Imposto Predial e Territorial Urbano (IPTU) de 2010 para 2013.

Já o projeto aprovado em 2015, no montante de $\mathrm{R} \$ 63$ milhões, prevê a implementação de novos sistemas, ampliação dos equipamentos do Parque de Tecnologia da Informação, capacitação de servidores e implantação de duas subprefeituras, sendo uma na Zona Norte e outra na Zona Sul da cidade. Dentre as vantagens de subprefeituras, a maior delas é quanto à proximidade dos serviços de atendimento vinculada às demandas reais dos moradores no território.

Prevista para 2016, a inauguração do Novo Paço Municipal pode ser considerado o símbolo da modernização da gestão, dado este que concentrará, em um mesmo espaço central e acessível, as secretarias atualmente espalhadas pelo território. Fruto de uma parceria Público Privada em uma das Operações Urbanas Consorciadas aprovadas, o Novo Paço também busca revitalizar a região central do município.

Outra ação tomada a fim de tornar a prestação de serviços públicos mais eficientes, conforme a literatura da Nova Gestão Pública aponta, foi a consolidação de um contrato de gestão para o principal hospital do município, o Hospital Municipal Antônio Giglio, referência para atendimento de média e alta complexidade para a região oeste da metrópole paulista. Em abril de 2015 uma Organização Social, selecionada por licitação pública, assumiu a gestão do hospital, visando sua modernização e aperfeiçoamento dos serviços prestados, bem como tendo por contrato a função de ampliá-los.

Há ainda a implantação do Monitora Osasco, sistema em desenvolvimento que centralizará informações a respeito dos projetos estratégicos monitorados pela SEPLAG Osasco em tempo real e de forma colaborativa. Desta maneira, iniciativas de aumento da transparência e fortalecimento do controle social também fazem parte da agenda de modernização em implantação no município. Com a ampliação Portal da Transparência, a Prefeitura passou a disponibilizar mais dados referentes a gastos e receitas em tempo real.

\subsubsection{Corpo técnico: os atores da reforma}

A prioridade política dada à agenda reformista foi crucial para sua implantação no município, e a participação do corpo técnico da SEPLAG Osasco deve ser considerada como de suma importância para a viabilização do Planejamento Estratégico.

Os dois atores-chave deste processo são a secretária de Planejamento e Gestão, Dulce Helena Cazzuni, e seu secretário adjunto, Alexandre Guerra. Dulce Cazzuni participou, em âmbito federal, da construção do Plano Brasil sem Miséria e, por sua vez, Alexandre Guerra atualmente é doutorando do Programa de Administração e Governo da Fundação Getúlio Vargas, o que aproximou a temática da modernização em sua atuação acadêmica e profissional.

O corpo técnico da SEPLAG Osasco é composto, majoritariamente, por técnicos especializados em administração e administração pública, além de economistas, advogados, geógrafos, dentre outros (Guerra et al., 2016). Do total de técnicos, $52 \%$ possuem algum tipo de especialização correlata ao tema, 33\% são mestres, $10 \%$ doutores e $5 \%$ pós-doutores. Esta especialização multidisciplinar permitiu melhores respostas aos problemas gerenciais encontrados pela administração pública. 


\subsubsection{Perspectivas e cenários futuros}

Além das iniciativas destacadas na área de planejamento e modernização dos sistemas de gestão, a recente queda no crescimento da arrecadação, somada à queda no Fundo de Participação Municipal, impactou o acompanhamento da execução orçamentária do município pela SEPLAG Osasco visando à garantia dos projetos estratégicos e a melhor distribuição e utilização dos recursos financeiros por parte das secretarias.

As ações para o fortalecimento institucional apresentam melhoria nos processos e fluxos internos e melhor relação com os convenentes, o que favorece não apenas a execução dos projetos atuais, como amplia as possibilidades de captação de recursos e execução de projetos.

Dentre os projetos com captação de recursos recente está a implantação de Central de Monitoramento Integrada, projeto inovador que busca potencializar a tomada de decisões ao centralizar e facilitar o acesso às informações de diferentes setores, como trânsito, segurança, saúde, habitação, dentre outros.

\subsection{0 caso do município de Niterói}

A SEPLAG Niterói originou-se a partir da Controladoria Geral do Município, responsável na gestão anterior por auxiliar a tomada de decisões e realizar o controle, com foco na contabilidade da Prefeitura, além de zelar pelo planejamento municipal, no que diz respeito ao cumprimento das exigências legais relativas ao ciclo orçamentário - criação do PPA, Lei de Diretrizes Orçamentárias (LDO) e Lei Orçamentária Anual (LOA). O propósito com a criação da SEPLAG Niterói na municipalidade foi o de incorporar funções para além do controle que permitissem foco em novos atributos nas áreas de planejamento estratégico e modernização da gestão.

A grande motivação para a criação desta institucionalidade no município de Niterói deveu-se à grave crise fiscal herdada da gestão anterior. Em diversos discursos oficiais e em entrevistas do Prefeito Rodrigo Neves essa grave crise fiscal e a necessidade de um "choque de gestão" foram enfatizados.

Os compromissos com o ajuste fiscal e a modernização da gestão assumidos nos primeiros dias de governo viriam a ser reiterados desde então pela atual gestão como política prioritária de governo para dar suporte ao desenvolvimento de outras iniciativas nas áreas finalísticas como saúde, educação e infraestrutura urbana. $\mathrm{O}$ descumprimento das diretrizes da LRF e a inadimplência da Prefeitura no Serviço Auxiliar de Informações para Transferências Voluntárias (CAUC) do Tesouro Nacional inviabilizavam empréstimos e financiamentos, além de impactarem negativamente nas transferências de recursos para o município. Tal motivação inicial de crise fiscal e necessidade da retomada da capacidade de investimento promoveram no município diversas iniciativas na área de gestão de inspiração reformista.

\subsubsection{A cultura de planejamento estratégico e o modelo de acordo de resultados}

A primeira estratégia para lidar com os desafios na área de gestão no município foi a realização de um "Plano de 100 dias" durante o governo de transição. O Plano definiu 90 objetivos em diversas áreas da administração e obteve o cumprimento de $90 \%$ das metas estabelecidas. O acompanhamento da execução das metas fora realizado pela SEPLAG Niterói, sendo esta primeira estratégia impulsionadora de outras iniciativas no município que promovessem a criação de uma "cultura de planejamento" junto aos órgãos da administração direta e indireta.

Concluída a fase de realização deste primeiro plano emergencial, a SEPLAG Niterói passa a liderar a construção de planos anuais junto aos órgãos e entidades. Nascem então os Planos de Metas anuais nos quais as Secretarias, Fundações e Autarquias ficaram responsáveis por definir cinco metas prioritárias: três finalísticas, uma de ajuste fiscal e uma de modernização da gestão. Para facilitar o monitoramento por área de resultado, os órgãos e entidades municipais foram divididos em três eixos Social; Infraestrutura e Desenvolvimento Sustentável; e Gestão Pública - e possuem monitoramento online pelo sistema GPweb.

Paralelamente à realização dos planejamentos de metas anuais, a SEPLAG passa a estabelecer como prioridade a criação de um planejamento estratégico de longo prazo que incluísse a participação da sociedade civil. Logo no início do governo iniciamse as tratativas, junto ao Movimento Brasil Competitivo (MBC) e a Associação Conselho Empresarial e Cidadania de Niterói (ACEC), para viabilizar investimentos capazes de realizar a construção de um plano estratégico de 20 anos para Niterói, com apoio técnico de consultorias com expertise na construção de planos com natureza semelhante em outros municípios e estados brasileiros.

Por meio de um fundrising mobilizado pelo MBC junto à ACEC - cuja rede congrega empresas e entidades de classe, que representam mais de $90 \%$ do PIB municipal - foram arrecadados recursos privados para a construção do "Plano Estratégico Niterói que Queremos 2033". Com o recurso foi contratada a consultoria que sustentou o desenvolvimento do projeto com apoio técnico e metodológico inspirado na experiência de Belo Horizonte e os estados de Minas Gerais, Rio de Janeiro e Espírito Santo.

A elaboração do "Plano Niterói que Queremos 2033" envolveu o levantamento de um diagnóstico profundo sobre o município e um amplo processo de escuta da sociedade. A etapa participativa do Plano envolveu pesquisa online por meio do site ${ }^{i v}$ com cinco mil questionários respondidos; entrevistas em profundidade com quarenta personalidades reconhecidas no município, em diferentes áreas de atuação; participação de mais de mil pessoas em um congresso presencial; e ausculta de mais de cinco mil crianças por meio de um concurso de redação e desenho nas escolas municipais com o tema "Niterói que Queremos".

O "Plano Niterói que Queremos 2033" foi lançado em 22 de novembro de 2014, aniversário de 441 anos da cidade, e apresentou aos niteroienses metas divididas em sete grandes áreas de resultado: i) Niterói Mais Organizada e Segura (mobilidade, desenvolvimento e ordenamento urbano e segurança); ii) Saudável (saúde, saneamento básico e gestão de resíduos); iii) Escolarizada 
e Inovadora (educação e ciência e tecnologia); iv) Próspera e Dinâmica (desenvolvimento econômico e inserção produtivo); v) Vibrante e Atraente (meio-ambiente, cultura, esporte, lazer e entretenimento); vi) Inclusiva (igualdade de oportunidades); e vii) Eficiente e Comprometida (gestão pública e integração regional).

Além dos objetivos de médio e longo prazos, o Plano estabeleceu metas de curto prazo a serem cumpridas até o final da gestão (2016) que foram organizadas por uma carteira de 32 projetos estruturadores diretamente vinculados às sete áreas de resultados supracitadas. Ainda que de curto prazo, as metas representam intenções ambiciosas, como: tornar Niterói a primeira cidade do país com mais de 500 mil habitantes a ter todas as crianças do ensino infantil cursando escola em horário integral e $100 \%$ de todas as regiões a terem acesso a esgoto e água tratada.

O monitoramento da execução dos 32 projetos estruturadores é acompanhado por um Escritório de Gerenciamento de Projetos Estratégicos diretamente vinculado ao gabinete do Prefeito e acompanhado pela sociedade por meio do site Niterói Feita por Vocêt

\subsubsection{Iniciativas de modernização da gestão}

A situação encontrada no diagnóstico inicial do município de Niterói, em relação aos sistemas de informação gerenciais, identificou a coexistência de 47 sistemas de protocolo, 11 de folha de pagamento e 10 sistemas contábeis. Ademais, o fechamento das contas públicas e geração de relatórios gerenciais eram operados e consolidados em planilhas de Excel.

Diante de tal diagnóstico, a necessidade de promover a integração entre os sistemas de gestão tornou-se prioridade dentro das estratégias de modernização da agenda reformista no município. Identificou-se a oportunidade de efetivar um Termo de Cooperação junto ao Governo do Estado do Rio de Janeiro, que por meio da SEPLAG Niterói e do Centro de Tecnologia da Informação e Comunicação (PRODERJ) viabilizou o apoio técnico e financeiro na execução do software livre de gestão municipal e-cidade.

Tal software, disponível gratuitamente no Portal do Software Público Brasileiro (SPB), possui diferentes módulos nas áreas financeira, recursos humanos, patrimônio e tributária, que oferecem a possibilidade de integrar todas as informações em uma mesma base de dados para promover a racionalização de gastos - por meio de informações sistematizadas, digitalizadas e fidedignas oferecendo subsídios ao gestor para tomada de decisões estratégicas.

Niterói, por se tratar de um município de grande porte, efetivou parceria com o Estado do Rio de Janeiro, na qual foram disponibilizados $R \$ 5$ milhões em investimento para a implantação do e-cidade, sob a prerrogativa de que a Prefeitura investisse outros $\mathrm{R} \$ 9$ milhões. Tal investimento, por parte da prefeitura de Niterói, foi viabilizado por meio de financiamento do PMAT que, além de suportar a implantação do e-cidade, garantiu recursos para outras frentes de modernização em curso, como: atualização do Plano Diretor de Tecnologia de Informação e Comunicação (PDTIC); aquisições para suprir a defasagem do parque tecnológico; implantação do modelo de Gestão para Resultados; redesenho de processos e estrutura organizacional; capacitações aos servidores; melhoria da transparência, entre outras.

Os ganhos destacados pelo município em relação à maior integração das informações financeiras e administrativas por meio do software e-cidade são grandes. De acordo com a Prefeitura, por meio do e-cidade foi possível garantir agilidade na tramitação dos processos e na execução do orçamento, além de propiciar informações fidedignas e atualizadas para disponibilização em tempo real no Portal da Transparência ${ }^{\text {vi. }}$.

A implantação dos módulos do e-cidade nos órgãos ainda não foi finalizada. Entretanto, a utilização do software por Niterói já tem despertado a atenção de outros municípios interessados em conhecer a experiência, como as Prefeituras de Itaperuna (RJ), Cachoeiras de Macacu (RJ) e Natal (RN).

\subsubsection{Corpo técnico: os atores da reforma}

A participação do corpo técnico da SEPLAG Niterói deve ser considerada como de suma importância para que o modelo de "Choque de Gestão" fosse viabilizado. Duas atrizes-chave lideraram a agenda de reforma e tiveram papel de destaque como secretárias da SEPLAG Niterói: Patrícia Audi e Giovanna Victer. Ambas pertencem à carreira de Especialistas em Políticas Públicas e Gestão Governamental (EPPGG) do Governo Federal, respectivamente da $3^{\underline{a}}$ e $13^{a}$ turma.

Enquanto Patrícia, secretária da SEPLAG Niterói de janeiro de 2013 a fevereiro de 2015, atuou em posições estratégicas em órgãos como INSS, Ministério do Planejamento e Secretaria de Assuntos Estratégicos na Presidência da República, Giovanna Victer, atualmente secretária da SEPLAG, atuou no Ministério das Cidades e no Programa de Modernização do governo federal no âmbito do Ministério do Planejamento. Especificamente no caso de Patrícia, a EPPGG teve também experiência na esfera estadual, a Secretaria de Direitos Humanos do Rio de Janeiro quando, à época, Rodrigo Neves era secretário.

Os subsecretários que compõem a SEPLAG Niterói também são servidores de carreira nas áreas de planejamento e controle advindos do Estado do Rio de Janeiro. Porém, a imensa maioria da equipe da Secretaria é composta por servidores com cargos em comissão. E a não existência da carreira de gestor público no município em áreas estratégicas tende a prejudicar a continuidade dos legados desta gestão, sendo necessária a criação de um concurso público para suprir essa lacuna.

\subsubsection{Perspectivas e cenários futuros}

Especificamente na área de gestão, e no que diz respeito às estratégias que compõem a base da agenda reformista no município, são prioridades a partir de 2017: a execução dos projetos estruturadores no escopo do "Niterói que Queremos" por meio do modelo de gestão para resultados; o redesenho de processos e da estrutura organizacional; o desenvolvimento de competências dos servidores; a realização de novos concursos nas áreas de saúde, gestão pública e educação; a instalação de um novo modelo de 
governança para as Parcerias Público-Privadas (PPPs) e a elaboração de um Plano Diretor de TICs.

$\mathrm{Na}$ área de planejamento, outra novidade é a sua associação mais estreita com a execução orçamentária. Antes a execução orçamentária era realizada na Secretaria de Fazenda e, a partir do início de 2015, passou a ser vinculada a área de planejamento da SEPLAG, buscando refletir a integração dos projetos estruturadores do "Plano Niterói que Queremos" com o PPA, LDO e LOA. Iniciativas de aumento da transparência e fortalecimento do controle social também é pauta.

No final de 2015 foi aprovada uma Lei que cria o Conselho de Transparência e Controle Social no município com a finalidade de garantir maior participação da sociedade civil na fiscalização e propostas de melhoria na gestão das contas públicas.

\section{ANÁlise COMPARADA DOS CASOS RELATADOS E DISCUSSÃO CRİTICA}

Os elementos que favorecem alianças e coalizões em torno da reforma gerencial nos estados identificados por Abrucio e Gaetani (2006, p. 17) também foram verificados no contexto dos municípios estudados e podem ser sintetizados conforme quadro abaixo:

Quadro 1 - Comparação de casos

\begin{tabular}{|c|c|c|c|}
\hline $\begin{array}{c}\text { Fatores } \\
\text { que } \\
\text { favorece } \\
\text { m } \\
\text { reforma } \\
\text { gerencial }\end{array}$ & Osasco & Niterói & Comparação \\
\hline $\begin{array}{l}\text { Efeito da } \\
\text { questão } \\
\text { fiscal }\end{array}$ & $\begin{array}{c}\text { Queda no } \\
\text { crescimento } \\
\text { da } \\
\text { arrecadaçã } \\
\text { o e passivo } \\
\text { de projetos } \\
\text { com } \\
\text { recursos } \\
\text { federais não } \\
\text { executados. } \\
\text { Prestações } \\
\text { de contas } \\
\text { de } \\
\text { convênios } \\
\text { glosadas e } \\
\text { irregularida } \\
\text { des no } \\
\text { CAUC. }\end{array}$ & $\begin{array}{l}\text { Herança de } \\
\text { grave } \\
\text { situação } \\
\text { fiscal e } \\
\text { irregularida } \\
\text { des no } \\
\text { CAUC } \\
\text { mobilizaram } \\
\text { necessidad } \\
\text { e de ajuste } \\
\text { e "choque } \\
\text { de gestão". }\end{array}$ & $\begin{array}{c}\text { Grande peso nos } \\
\text { dois casos da } \\
\text { questão fiscal para } \\
\text { busca de estratégias } \\
\text { de reforma } \\
\text { administrativa para } \\
\text { viabilizar a } \\
\text { organização das } \\
\text { contas públicas. }\end{array}$ \\
\hline $\begin{array}{c}\text { Inovações } \\
\text { administra } \\
\text { tivas que } \\
\text { geraram } \\
\text { path } \\
\text { dependen } \\
\text { ce }\end{array}$ & $\begin{array}{c}\text { Repercussã } \\
\text { o do caso } \\
\text { de MG e } \\
\text { AC. } \\
\text { Participação } \\
\text { de } \\
\text { consultoria } \\
\text { de } \\
\text { referência } \\
\text { no modelo } \\
\text { de } \\
\text { planejament } \\
\text { o adotado e } \\
\text { trajetória } \\
\text { dos } \\
\text { burocratas } \\
\text { em outras } \\
\text { esferas de } \\
\text { governo e } \\
\text { conhecimen } \\
\text { to } \\
\text { acadêmico } \\
\text { nas linhas } \\
\text { de políticas } \\
\text { públicas e } \\
\text { administraç }\end{array}$ & $\begin{array}{c}\text { Modelos de } \\
\text { planejament } \\
\text { o } \\
\text { estratégico, } \\
\text { núcleo de } \\
\text { gestão } \\
\text { estratégica } \\
\text { e gestão } \\
\text { para } \\
\text { resultados } \\
\text { vieram de } \\
\text { consultoria } \\
\text { de } \\
\text { referência } \\
\text { na área } \\
\text { pública, } \\
\text { aplicados } \\
\text { em casos já } \\
\text { consolidado } \\
\text { s como BH, } \\
\text { MG, RJ e } \\
\text { ES. As } \\
\text { trajetórias } \\
\text { das } \\
\text { secretárias } \\
\text { da SEPLAG }\end{array}$ & $\begin{array}{c}\text { Ambos se inspiraram } \\
\text { em experiências de } \\
\text { repercussão } \\
\text { nacional, e contam } \\
\text { em seu corpo com } \\
\text { burocratas que } \\
\text { tiveram contato ou } \\
\text { estudaram tais } \\
\text { casos, bem como } \\
\text { contaram com } \\
\text { consultorias } \\
\text { especializadas em } \\
\text { gestão pública na } \\
\text { construção da } \\
\text { proposta de reforma. }\end{array}$ \\
\hline
\end{tabular}

\begin{tabular}{|c|c|c|c|}
\hline & $\begin{array}{c}\text { ão pública e } \\
\text { governo. }\end{array}$ & $\begin{array}{l}\text { no Governo } \\
\text { Federal } \\
\text { inspiraram a } \\
\text { base da } \\
\text { agenda } \\
\text { reformista } \\
\text { em Niterói. }\end{array}$ & \\
\hline $\begin{array}{l}\text { Peso dos } \\
\text { policies } \\
\text { entrepreu } \\
\text { ners }\end{array}$ & $\begin{array}{c}\text { Equipe com } \\
\text { técnicos } \\
\text { formados } \\
\text { especificam } \\
\text { ente em } \\
\text { Administraç } \\
\text { ão Pública e } \\
\text { Governo, } \\
\text { economista } \\
\text { s e } \\
\text { geógrafos, } \\
\text { além de } \\
\text { experiência } \\
\text { s em } \\
\text { diferentes } \\
\text { âmbitos de } \\
\text { governo, } \\
\text { inclusive } \\
\text { federal. } \\
\text { Empoderam } \\
\text { ento do } \\
\text { Chefe do } \\
\text { Poder } \\
\text { Executivo } \\
\text { para que a } \\
\text { SEPLAG } \\
\text { atue de } \\
\text { forma } \\
\text { transversal } \\
\text { e com } \\
\text { poder de } \\
\text { mediação e } \\
\text { decisão } \\
\text { entre as } \\
\text { secretarias. }\end{array}$ & $\begin{array}{c}\text { Equipe de } \\
\text { alto escalão } \\
\text { da SEPLAG } \\
\text { formada por } \\
\text { técnicos de } \\
\text { carreira } \\
\text { (EEPPGGs) } \\
\text { do governo } \\
\text { federal com } \\
\text { histórico de } \\
\text { trabalho em } \\
\text { áreas } \\
\text { estratégicas } \\
\text { de gestão. } \\
\text { Empoderam } \\
\text { ento do } \\
\text { Chefe do } \\
\text { Poder } \\
\text { Executivo } \\
\text { da SEPLAG } \\
\text { na } \\
\text { coordenaçã } \\
\text { o de } \\
\text { iniciativas } \\
\text { de gestão } \\
\text { para o } \\
\text { conjunto de } \\
\text { órgãos. }\end{array}$ & $\begin{array}{l}\text { A qualidade técnica } \\
\text { dos gestores que } \\
\text { impulsionaram a } \\
\text { reforma gerencial em } \\
\text { ambos os municípios } \\
\text { foi de suma } \\
\text { importância. } \\
\text { Ademais, verificou-se } \\
\text { que a experiência no } \\
\text { Governo Federal das } \\
\text { secretárias das } \\
\text { pastas constituiu-se } \\
\text { como repertório para } \\
\text { estruturar as } \\
\text { estratégias de } \\
\text { modernização da } \\
\text { gestão e } \\
\text { planejamento } \\
\text { implementado. A } \\
\text { prioridade política } \\
\text { para esta a agenda } \\
\text { reformista e a defesa } \\
\text { dessa prioridade } \\
\text { junto aos secretários } \\
\text { de outras pastas } \\
\text { também foram } \\
\text { fundamentais em } \\
\text { ambos os casos. }\end{array}$ \\
\hline $\begin{array}{l}\text { A "janela } \\
\text { de } \\
\text { oportunida } \\
\text { de" aberta } \\
\text { pela ideia } \\
\text { mobilizad } \\
\text { ora do } \\
\text { "Choque } \\
\text { de } \\
\text { Gestão" }\end{array}$ & $\begin{array}{l}\text { Necessidad } \\
\text { e de } \\
\text { inovação da } \\
\text { Gestão. } \\
\text { Abertura da } \\
\text { cúpula } \\
\text { administrati } \\
\text { va para } \\
\text { implantação } \\
\text { da } \\
\text { contratualiz } \\
\text { ação de } \\
\text { resultados. }\end{array}$ & $\begin{array}{c}\text { Priorização } \\
\text { da agenda } \\
\text { de gestão } \\
\text { no governo } \\
\text { para } \\
\text { garantir } \\
\text { aumento da } \\
\text { capacidade } \\
\text { de } \\
\text { investiment } \\
\text { os, questão } \\
\text { fiscal e } \\
\text { escolha do } \\
\text { "choque de } \\
\text { gestão" } \\
\text { como } \\
\text { legado } \\
\text { político. }\end{array}$ & $\begin{array}{l}\text { Apesar de distintas } \\
\text { motivações que } \\
\text { levaram à abertura } \\
\text { da "janela de } \\
\text { oportunidade", } \\
\text { ambos os casos se } \\
\text { basearam na } \\
\text { necessidade de } \\
\text { renovação e } \\
\text { profissionalização da } \\
\text { gestão para enfrentar } \\
\text { a crise fiscal e } \\
\text { orquestrar a } \\
\text { implementação de } \\
\text { políticas inovadoras. }\end{array}$ \\
\hline
\end{tabular}

Ambos os casos apresentados criam o papel de uma secretaria de planejamento, como orientadora da estratégia de gestão de políticas públicas no município, atuando no fortalecimento institucional dos diferentes órgãos, na promoção do ajuste fiscal e na busca de boas práticas de modernização administrativa.

Conforme foi possível notar, o peso da questão fiscal foi forte em ambos os casos estudados para motivar estratégias de reforma gerencial, tendo em vista problemas em relação a irregularidades Serviço Auxiliar de Informações para Transferências Voluntárias do Tesouro Federal (CAUC), e a ineficiência na execução dos projetos realizados por meio de transferências em gestões anteriores.

No que diz respeito às inovações administrativas que geraram path dependence deve-se ressaltar a grande influência que o modelo de "Choque de Gestão" de Minas Gerais ainda possui na difusão das estratégias de reforma gerencial - mesmo considerando as críticas que diversos estudos apontam sobre os 
seus resultados (Borges, Freitas Junior \& Oliveira, 2008). Interessante notar que o modelo capitalizado politicamente pelo PSDB, como um de seus maiores legados, orienta a atuação de municípios governados por partidos de esquerda dos casos estudados.

Outro ponto relevante para destaque em relação ao path dependence é a influência verificada em ambos os casos de empresas de consultoria. Viu-se que para além da influência de bancos de experiência, redes e fóruns de gestão pública sugerida na análise de Abrucio e Gaetani (2006), a atuação das consultorias para governo como difusoras de modelos de base reformista deva ser considerada na análise.

Ainda que as consultorias voltadas à gestão pública também prestem serviços nos governos federal e estadual, no caso dos municípios estudados, em função da existência de burocracias mais frágeis, assumem papel fundamental para impulsionar as reformas na gestão pública. $O$ path dependence dos modelos de planejamento adotados em ambos os municípios estudados, por exemplo, foi estruturado com base na participação de consultorias voltadas à gestão pública e o corpo qualificado de consultores mostrou-se fundamental para apoiar a implementação das iniciativas e capacitar os servidores em novas metodologias de trabalho.

Por sua vez, a participação dos empreendedores de políticas mostrou-se o fator de maior relevância nas experiências de reforma gerencial estudadas. A experiência prévia no governo federal dos gestores destacada por Abrucio e Gaetani (2006), como fator impulsionador da reforma nos estados, pôde ser constatada nos casos de Osasco e Niterói, que também se vale de corpo técnico em diferentes setores da administração. A defesa política desta agenda de gestão como prioridade ao conjunto de secretarias, a criação da SEPLAG e a escolha de um quadro técnico também devem ser considerados como fatores e suma relevância nos casos estudados para mobilizar o choque de gestão.

No que diz respeito à natureza das iniciativas implementadas pelos municípios, pode-se inferir que no caso de Niterói a integração dos sistemas de modernização da gestão tem maior prioridade na agenda de reformas comparativamente a Osasco. Enquanto Niterói tem tomado decisões baseadas em sistemas de informação integrados de execução financeira e monitoramento de projetos (e-cidade e GPweb), em Osasco esse cenário ainda não é uma realidade. Há proposta de Centro Integrado de Monitoramento e Sistema próprio de Monitoramento de Projetos (Monitora Osasco) com previsão de ser realizada até o final da gestão.

Pelos dados apresentados, é possível corroborar a análise de Abrucio e Gaetani (2006), dado que os casos apresentam alianças e coalizões em torno da agenda de reforma gerencial. Por outro lado, há elementos que atualizam a discussão, como a necessidade de ampliar a reforma para temas mais próximos à sociedade civil e ampliação de ferramentas de accountability, avanços necessários, mas que ainda não foram plenamente executados pelas experiências estudadas.
O modelo de governança participativa adotado em ambos os casos ainda carece de avanços. Participação social e modelos de governança compartilhados são projetos elaborados e em início de inserção no caso de Osasco e Niterói mais restritos à etapa de elaboração dos planos estratégicos. Na etapa de implementação das políticas públicas a participação ainda precisa avançar no contexto de reformas e ser inserida com maior frequência nas agendas governamentais como um todo, o que inclui o governo eletrônico e a participação digital.

Em relação ao consenso em torno das experiências estudadas, as estratégias de planejamento mostraram-se bastante semelhantes em ambos os casos na forma de pactuação de metas e acordo de resultados junto aos órgãos dos municípios, elaboração participativa de planejamento estratégico de médio e longo prazos e a colocação de Escritório de Gerenciamento de Projetos. Tais modelos já bastante consolidados em outros casos no país e disseminados por consultorias voltadas ao setor público.

Convém ressaltar que em ambos os casos o modelo de acordo de resultados ficou circunscrito ao planejamento estratégico e pactuação das metas, sem remuneração por desempenho aos servidores. Os contratos de gestão, típicos da NPM, não foram objeto da reforma gerencial capitaneada pelas SEPLAG nos municípios, ainda que tenham sido verificados na área de saúde de Osasco.

Abre-se a suposição de que essa ausência de ênfase nos contratos de gestão dentro do pacote de projetos da SEPLAG, nos casos estudados, pode ser derivada de certa dificuldade de assumir este modelo de gestão, pois se mostra como questão delicada para partidos de esquerda, que questionam os contratos de gestão considerando que viriam a contribuir para "terceirizar as funções do Estado" e perpetuar a lógica do "Estado mínimo".

As experiências analisadas, por ainda estarem em curso, não permitem avaliar em profundidade os aspectos que as diferem dos choques de gestão que as embasaram. Ainda que os casos sejam capazes de ilustrar casos relevantes de reforma gerencial, não devem ser considerados como suficientes para exaurir o tema, sendo necessário realizar investigações de maior fôlego para determinar o contexto próprio de reformas nos municípios brasileiros.

\section{CONSIDERAÇÕES FINAIS}

De acordo com a literatura, o modelo de reforma gerencial não é uma receita fechada, uma vez que pode e vem sendo aplicado por diferentes visões ideológicas, sendo que o principal fator é a busca por melhores resultados para as políticas públicas.

Os casos demonstram que a gestão por resultados ainda é referência para a administração pública, mas entende-se cada vez mais que o modelo em questão tem uma complexa aferição. A disseminação desse modelo - geralmente relacionado à plena execução de políticas públicas planejadas e pactuadas - tem sido amplamente disseminada por consultorias voltadas ao setor público. Nesse sentido, deve-se ser questionada a capacidade de 
inovação dessas experiências ou de "engessamento" da inovação das reformas gerenciais nos municípios.

A prioridade política e a participação de policies entrepreuners foram fundamentais para a implantação das ferramentas de gestão nos casos em questão, ressaltando a importância do desenvolvimento do campo de administração pública para uma crescente melhoria dos processos e instituições. Em ambos os casos a existência de atores formados e com atuação em cargos estratégicos na administração pública foram fundamentais para inserir este tema na agenda de gestão, cuja execução contou com apoio de consultorias experientes em reformas gerenciais.

Além da importância dos atores, ferramentas que permitam a participação popular e controle social são essenciais para 0 sucesso e perpetuação das iniciativas de reforma de gestão em ambientes democráticos, mas as experiências analisadas mostram que ainda é um desafio a ser aprofundado. Por se tratar de experiências ainda em curso, seus resultados poderão ser melhor avaliados a posteriori, momento no qual os resultados alcançados, bem como limites e dificuldades ficarão mais claros e sedimentados.

Após 20 anos da experiência de Reforma do Aparelho do Estado a literatura especializada e os casos estudados demonstram como o ideal de eficiência no setor público foi perpetuado, mesmo que tomando roupagens distintas.

O cenário político no Brasil atual é incerto, o que dificulta previsões sobre próximos passos. Mesmo assim, é possível destacar que ainda há muito que se avançar em contexto de municípios. As experiências mostram que há tentativas em curso, e principalmente, demonstram que há espaço para melhorias na gestão pública, sendo necessário avançar nos instrumentos e modelos que permitirão uma gestão pública mais eficiente.

Os contextos estudados destacam ainda a importância de promover novos estudos que questionem a natureza da difusão das experiências de base reformista. Já o cenário político conturbado coloca dúvidas quanto às estruturas atuais, podendo abrir diferentes caminhos para as experiências em curso. Por todo o contexto, entende-se que são necessários estudos mais profundos a respeito do alcance dos resultados no médio e longo prazos das iniciativas adotadas no campo da gestão pública brasileira.

\footnotetext{
i Ressaltamos a atuação da rede capitaneada pelo Conselho Nacional de Secretários de Estado de Administração (CONSAD) para o registro e divulgação de cases de reforma gerencial no país, por meio de seus fóruns e congressos anuais, que reúnem experiências de practioners e acadêmicos de diversos entes federativos na área de gestão pública.

ii A linha de crédito PMAT do BNDES destina-se a projetos de investimento nos municípios que visam à modernização da gestão pública. Tem como objetivo contribuir para a melhoria da eficiência da administração pública, com a geração do aumento de receitas e/ou redução do custo dos serviços públicos. O PMAT é uma das linhas de crédito mais acessadas pelos municípios para implementar projetos de modernização da gestão e aprimorar a administração tributária, considerando que é uma das únicas destinadas especificamente à melhoria da eficiência da gestão pública.
}

\section{REFERÊNCIAS BIBLIOGRÁFICAS}

Abrucio, F. L.; Gaetani, F. (2006). Avanços e perspectivas da gestão pública nos Estados: Agenda, aprendizado e coalizão. In: CONSAD e FUNDAP. Avanços e perspectivas da gestão públicas nos Estados. CONSAD e FUNDAP, p. 21-80

Bechelaine, C. H. O.; Silveira, M.; Neves, C. (2012). O modelo de gestão pública por Resultados em Minas Gerais analisado à luz da experiência do Programa Estado para Resultados. Revista do Serviço Público, v. 63, p. 411.

Bresser-Pereira, L. C. (1998). Reforma do Estado para a Cidadania. 1. ed. São Paulo: Editora 34, 368p.

Bernardi, B. B (2012). O conceito de dependência de trajetória (path dependence): definições e controvérsias teóricas. Revista Perspectivas, São Paulo, v. 41, http://www.scielo.br/pdf/rap/v46n5/a01v46n5.pdf jun. - jan, p. $137-167$.

Borges, A. F.; Freitas Junior, D. B. de; Oliveira, E. R. de (2008). Estratégia e administração pública: o caso do programa "choque de gestão" do Governo do Estado De Minas Gerais. Pretexto, Belo Horizonte, v. 9, n. 3, jul./set, p. 79106.

Crantschaninov, T. I. ; Medeiros, A. K. (2012). Dilemas da Gestão Pública no Pós-1988: Participação, Controle Social e Eficiência nos municípios do estado de São Paulo. In: XXXVI Encontro da ANPAD, 2012, Rio de Janeiro. Anais do XXXVI Encontro da ANPAD.

Freitas JR. (2009). Avaliação da administração pública gerencial em municípios por meio de indicadores. 2009. 139 p. Dissertação (mestrado em administração) - Universidade Federal de Lavras, Lavras.

Guerra, A.; Cazzuni, D.; Coelho, R.; Reinach, S.. (Org.) (2016). Planejamento público e gestão por resultados: uma experiência municipal aplicada. 1.ed. São Paulo: Hucitec, $255 \mathrm{p}$.

Kingdon, J. W (1995). Agendas, Alternatives and Public Policies. Longman, London.

Ibge - Instituto Brasileiro de Geografia e Estatística. Censo Demográfico 2010. Disponível em: < http://censo2010.ibge.gov.br/ > Acesso em: 25 de fevereiro de 2015

Moynihan, D. P., Pandey, S. K (2004). Testing How Management Matters in an Era of Government by Performance Management. In: Journal of Public Administration Research and Theory 15(3): 421-439.

O'toole, L.J., Meier, K.J (2015). Public management, context, and performance: In quest of a more general theory. Journal of Public Administration Research and Theory 25, 1: 237-56.

Pacheco, R. (2006). Brasil: avanços da contratualização de resultados no setor público. XI Congreso Internacional del CLAD sobre la Reforma del Estado y de la Administración Pública. Ciudad de Guatemala, 7 - 10 Nov.

Pnud - Programa das Nações Unidas para o Desenvolvimento. Relatório do Índice de Desenvolvimento Humano (IDH). Disponível em: < http://www.pnud.org.br/IDH/DH.aspx > Acesso em: 25 de fevereiro de 2015.

Schwarz, L. (2010). Experiência de Contratualização de Resultados no Governo Federal Brasileiro: Pesquisa com Órgãos Supervisores de Contratos de Gestão. Relatório de Pesquisa II. Brasília, dezembro de 2009. Disponível em: <http://www.gespublica.gov.br/biblioteca/pasta.2010-1208.3617032145/pasta.2010-04-

08.0042928925/Leticia\%20PRODUTO\%20II.pdf>. Acesso em 04 de abril de 2015.

iii Ver estudo de Bernardi (2012) a respeito da utilização do termo na ciência política.

iv Disponível em: www.niteroiquereremos.com.br

$\checkmark$ Disponível em: www.niteroiquereremos.com.br

vi Nos rankings de avaliação da transparência pública do Ministério Público Federal (MPF) e Controladoria Geral da União (CGU), entre os anos de 2015 e 2016, Niterói obteve destaque com a nota 10 e primeira colocação no Estado do Rio de Janeiro. 